Supporting Information

\title{
Influences of a solvent trap in ITO/PEN substrates on the performance of flexible perovskite solar cells and light-emitting diodes
}

Soyoung $\mathrm{Kim}^{1+}$, Heeyoon $\mathrm{Oh}^{1+}$, Inyoung Jeong ${ }^{2}$, Gumin Kang ${ }^{3}$, Minwoo Park ${ }^{1 *}$

S. Kim, H. Oh, Prof. M. Park

${ }^{1}$ Department of Chemical and Biological Engineering, Sookmyung Women's University, Seoul 04310, Korea

Dr. I. Jeong

${ }^{2}$ Photovoltaics Research Department, Korea Institute of Energy Research, Daejeon 34129, South Korea

Dr. G. Kang

${ }^{3}$ Nanophotonics Research Center, Korea Institute of Science and Technology (KIST), Seoul 02792, Korea

${ }^{+}$These authors equally contributed to this work.

*Corresponding author e-mail: mwpark@.sm.ac.kr 
Table S1. Hansen solubility parameters of the solvents and their absolute difference values from PEN.

\begin{tabular}{lcc}
\hline Materials & $\begin{array}{c}\text { Solubility } \\
\mathbf{p a r a m e t e r ~}(\boldsymbol{\delta})^{\left[\mathbf{M P a}^{\mathbf{0 . 5}}\right]}\end{array}$ & $\begin{array}{c}\text { Absolute difference from PEN }(\boldsymbol{\Delta} \boldsymbol{\delta}) \\
{\left[\mathbf{M P a}^{\mathbf{0 . 5}}\right]}\end{array}$ \\
\hline Isopropyl alcohol (IPA) & 23.5 & 2.7 \\
Acetone (ACE) & 20 & 0.8 \\
Toluene (TOL) & 18.2 & 2.6 \\
Chloroform (CHL) & 18.7 & 2.1 \\
Water & 47.8 & 27 \\
PEN & 20.8 & 0 \\
\hline
\end{tabular}



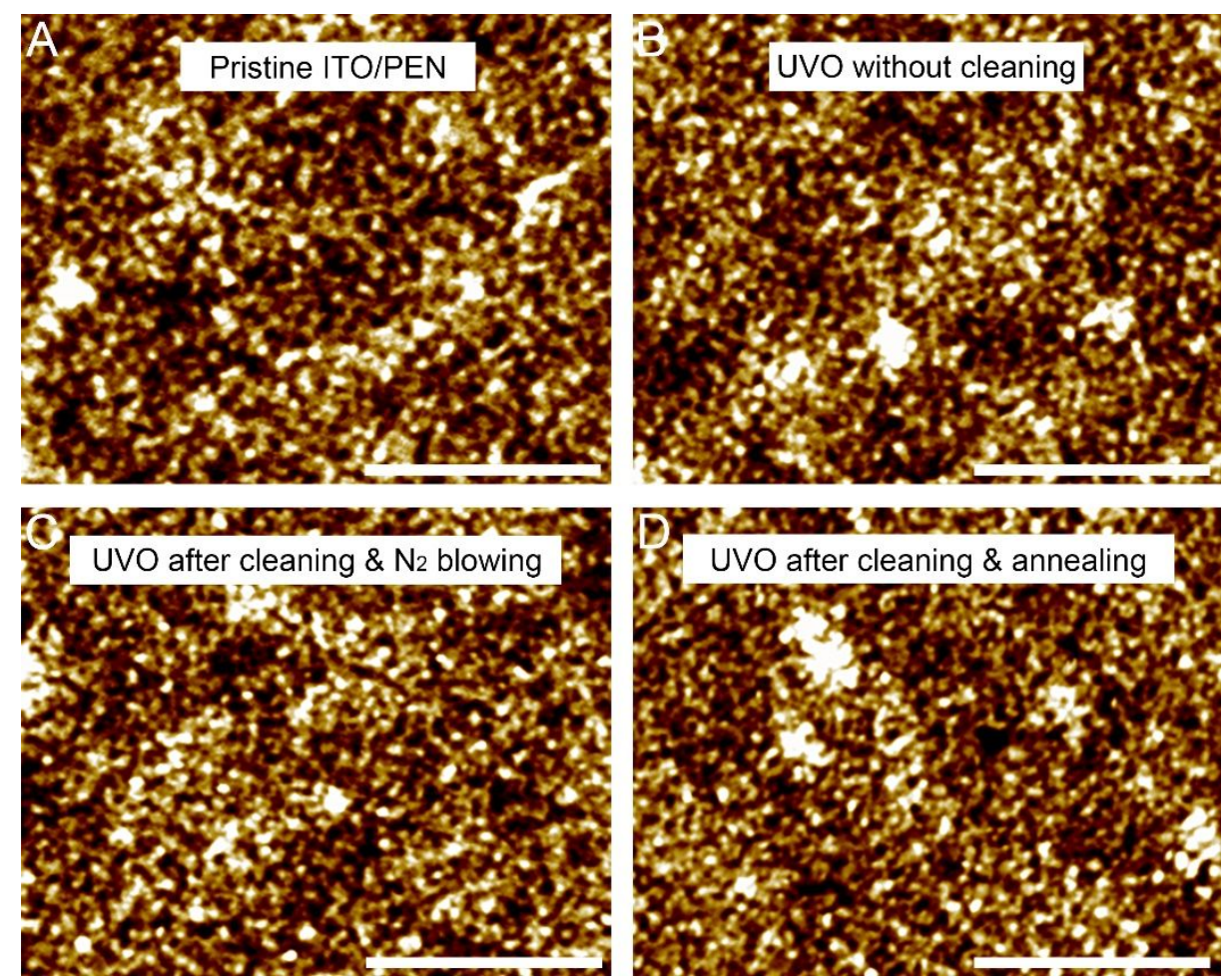

Figure S1. Topological AFM images obtained by the tapping mode: (A) pristine ITO/PEN, (B) ITO/PEN after UVO treatment for 20 min without cleaning, (C) ITO/PEN after cleaning and UVO treatment (dried at $\mathrm{N}_{2}$ environment) (as-prepared ITO/PEN), and (D) ITO/PEN after cleaning and thermal annealing (dried at $100^{\circ} \mathrm{C}$ for $3 \mathrm{~min}$ ) (annealed ITO/PEN). The inset scale bar $=2 \mu \mathrm{m}$. 


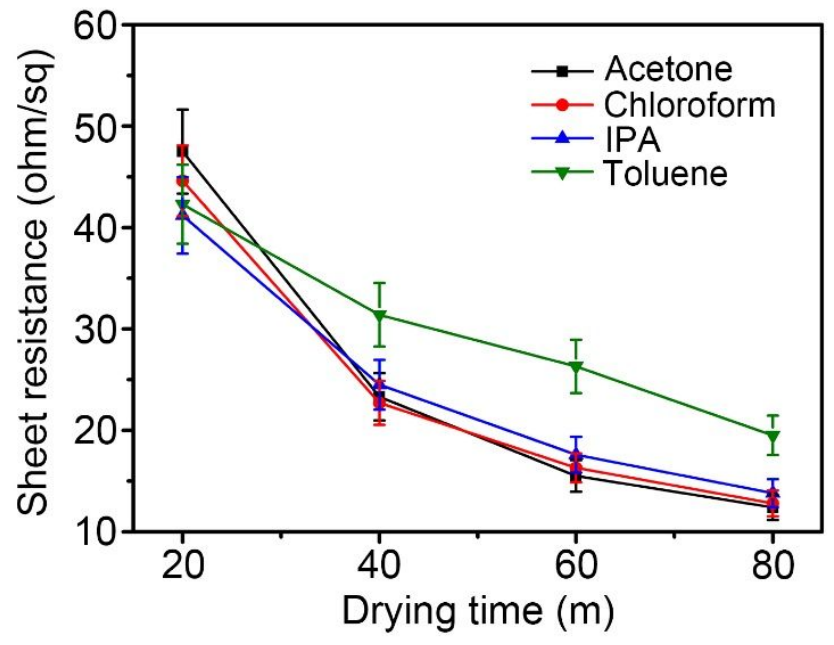

Figure S2. Sheet resistances of the as-prepared ITO/PEN according to the types of cleaning solvents and drying time. After drying the samples in $\mathrm{N}_{2}$ environment for given times (20-80 min), UVO treatment was performed for $20 \mathrm{~min}$. 

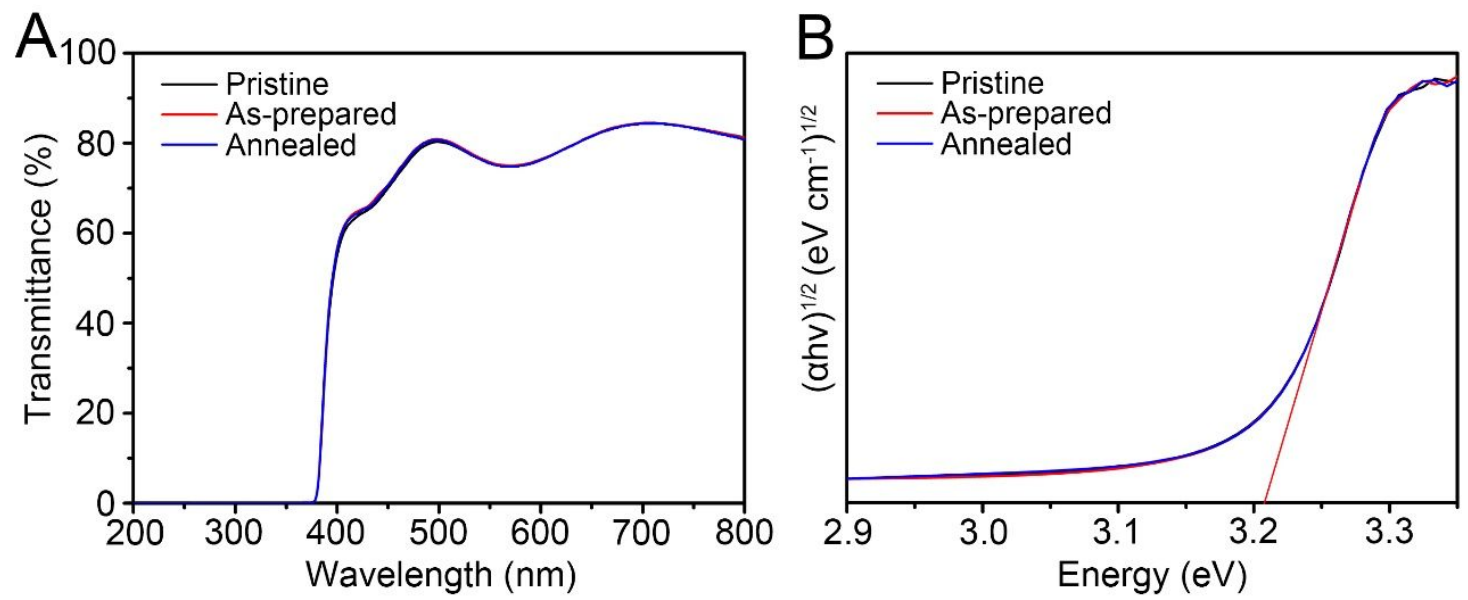

Figure S3. (A) Transmittance curves and (B) Tauc plots of the pristine, as-prepared, and annealed ITO/PEN. 


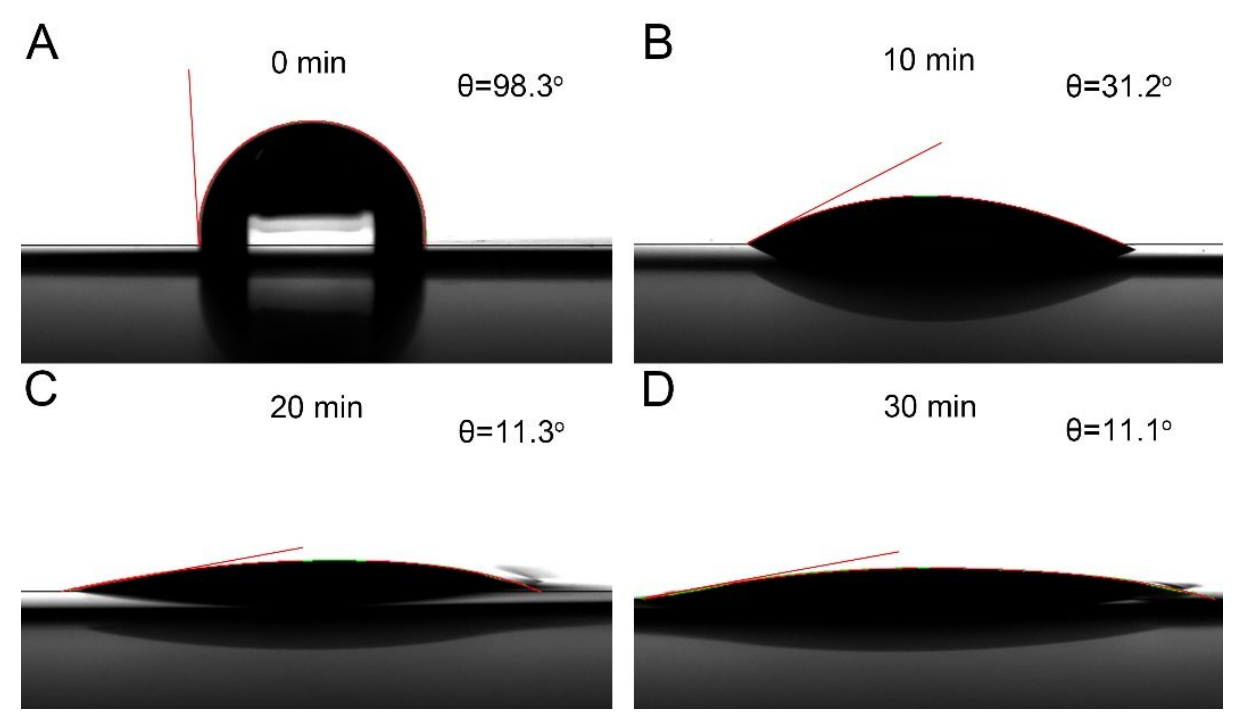

Figure S4. Cross-section OM images for contact angles of a water droplet on (A) pristine ITO/PEN, (B) UVO-treated ITO/PEN for $10 \mathrm{~min}$, (C) UVO-treated ITO/PEN for $20 \mathrm{~min}$, and (D) UVO-treated ITO/PEN for $30 \mathrm{~min}$. 
Table S2. Sheet resistances of the annealed ITO/PEN for annealing time and temperature.

\begin{tabular}{llll}
\hline & \multicolumn{3}{c}{ Temperature $\left[{ }^{\circ} \mathrm{C}\right]$} \\
Annealing time $[\mathrm{min}]$ & 50 & 100 & 150 \\
\hline 1 & $39.4 \Omega \mathrm{sq}^{-1}$ & $23.7 \Omega \mathrm{sq}^{-1}$ & $15.6 \Omega \mathrm{sq}^{-1}$ \\
3 & $37.6 \Omega \mathrm{sq}^{-1}$ & $14.4 \Omega \mathrm{sq}^{-1}$ & $14.0 \Omega \mathrm{sq}^{-1}$ \\
5 & $34.5 \Omega \mathrm{sq}^{-1}$ & $14.2 \Omega \mathrm{sq}^{-1}$ & $14.1 \Omega \mathrm{sq}^{-1}$ \\
7 & $27.5 \Omega \mathrm{sq}^{-1}$ & $14.3 \Omega \mathrm{sq}^{-1}$ & $13.9 \Omega \mathrm{sq}^{-1}$ \\
\hline
\end{tabular}




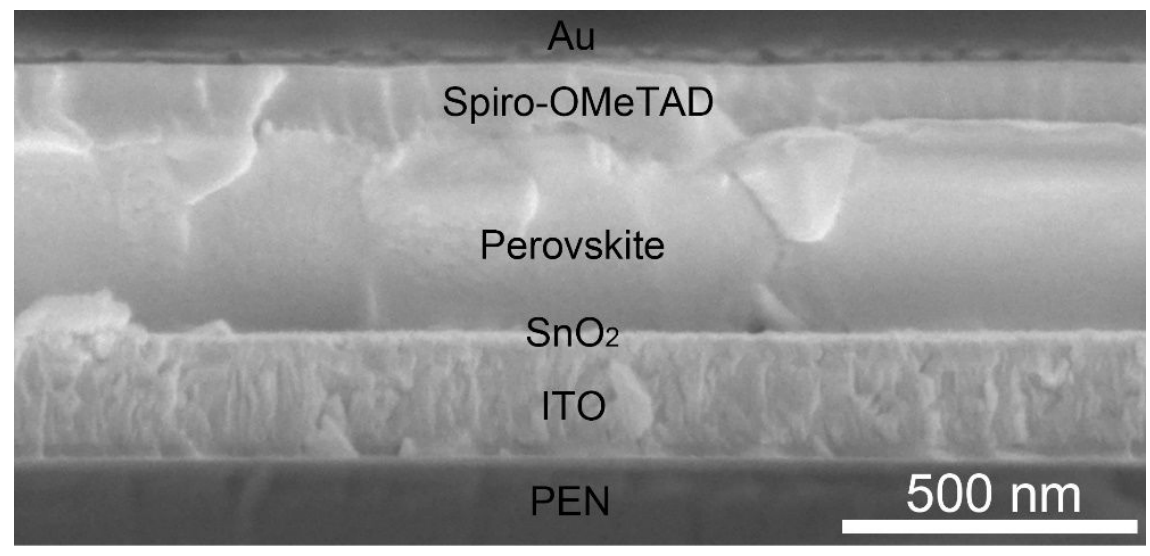

Figure S5. Cross-section SEM image of a flexible PSC. 
Table S3. Time-resolved photoluminescence (TRPL) parameters of the perovskite films, fitted using a bi-exponential decay function. ${ }^{\text {a) }}$

\begin{tabular}{|l|c|c|c|c|c|}
\hline Substrate & $\mathrm{a}_{1}$ & $\tau_{1}[\mathrm{~ns}]$ & $\mathrm{a}_{2}$ & $\tau_{2}[\mathrm{~ns}]$ & $\tau_{\text {avg }}[\mathrm{ns}]^{\mathrm{b})}$ \\
\hline As-prepared & 0.707 & 19.08 & 0.293 & 70.67 & 34.19 \\
\hline Annealed & 0.750 & 10.18 & 0.250 & 41.83 & 18.09 \\
\hline
\end{tabular}

${ }^{\text {a) }}$ Fit function $=a_{1} e^{-t / \tau_{1}}+a_{2} e^{-t / \tau_{2}}$

${ }^{\mathrm{b})} \tau_{\text {avg }}=\left(\sum_{i} a_{i} \tau_{i}\right) /\left(\sum_{i} a_{i}\right)$, where $\sum_{i} a_{i}=1$ 

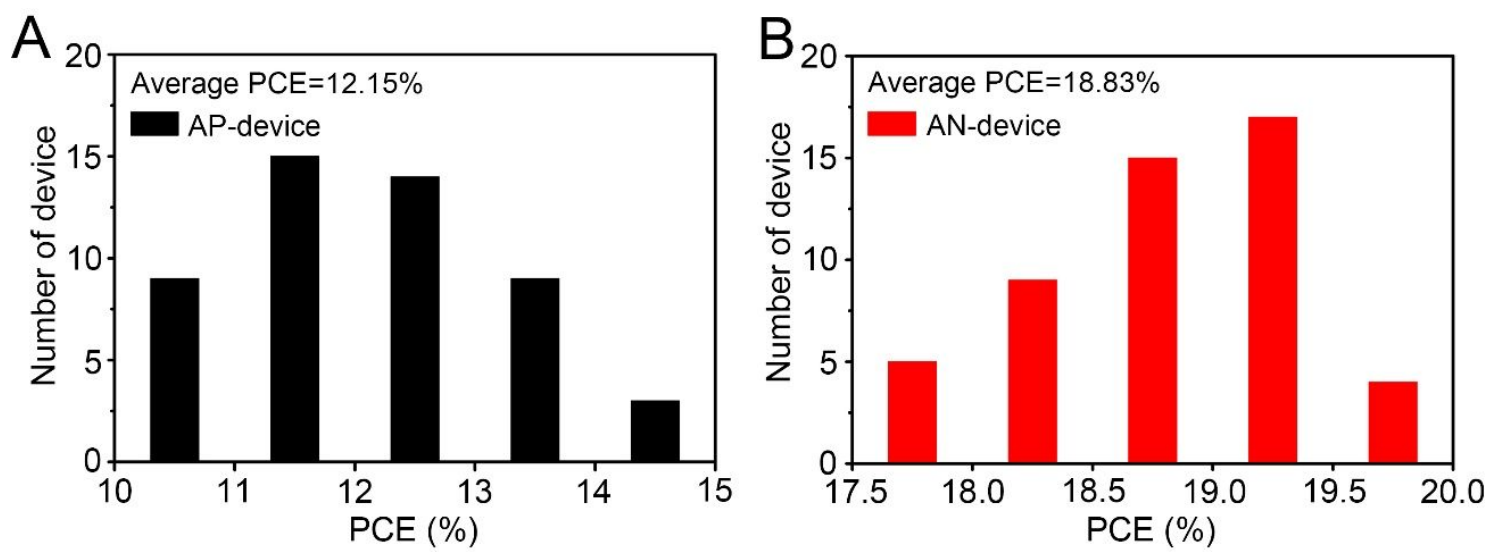

Figure S6. PCE histograms of (A) AP-devices and (B) AN-devices. 


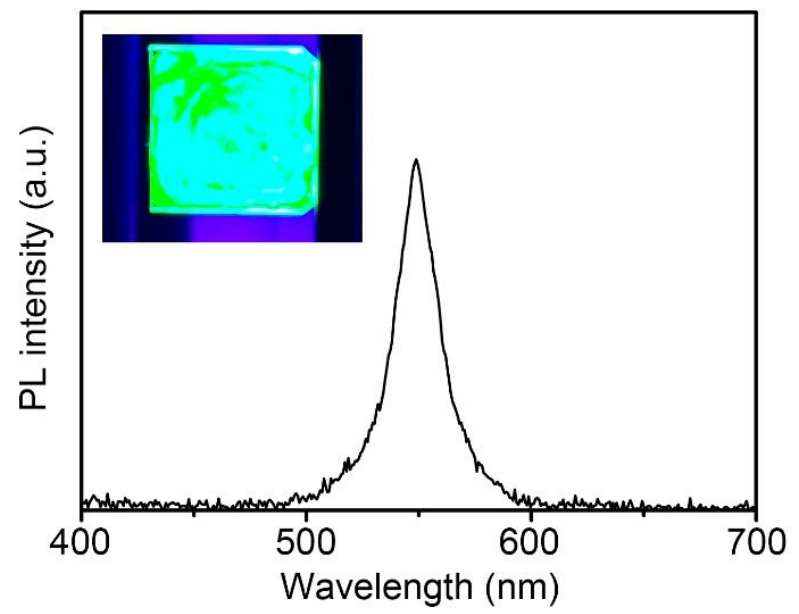

Figure S7. Steady-state PL spectrum of the $\mathrm{MAPbBr}_{3} / \mathrm{PVP}$ composite film. The inset photograph shows the emission of PL (incident light: UV $365 \mathrm{~nm}$ ). 

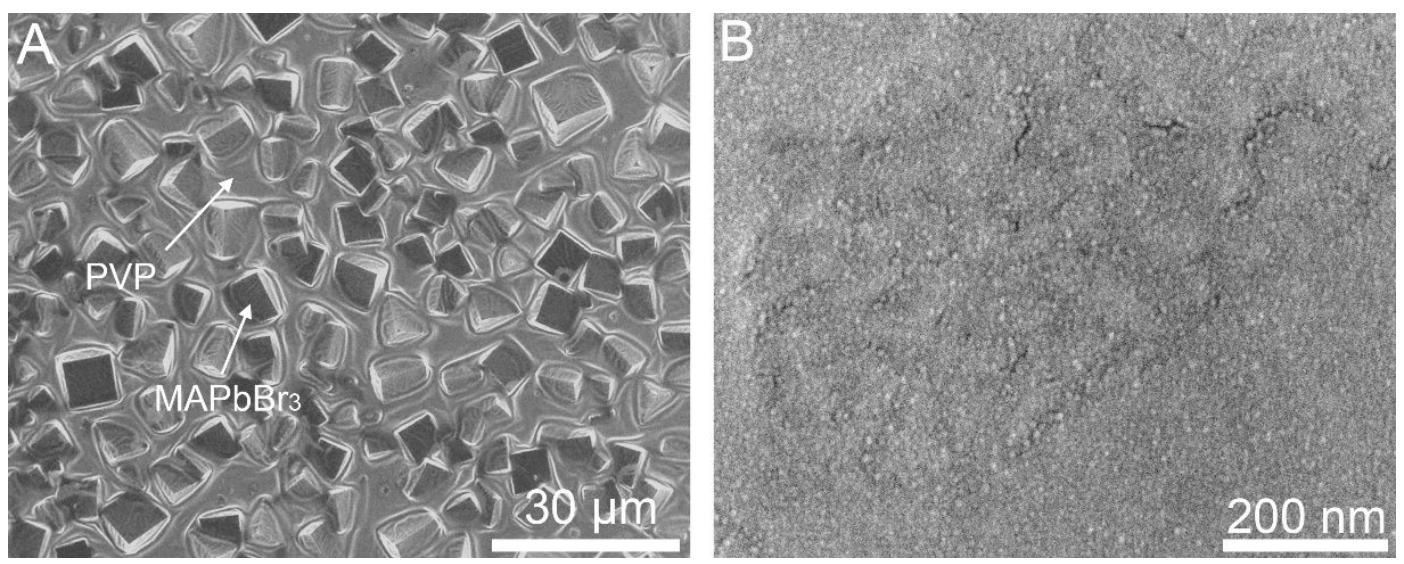

Figure S8. (A) SEM image of the $\mathrm{MAPbBr}_{3} / \mathrm{PVP}$ composite film. (B) Magnified SEM image of a $\mathrm{MAPbBr}_{3}$ crystal. 